\title{
Health Effects of Air Pollution: Evidence from China
}

\author{
Boya Liu \\ Institute for Capacity Development, International Monetary Fund, Washington D.C., USA \\ Email: bliu2@imf.org
}

How to cite this paper: Liu, B.Y. (2019) Health Effects of Air Pollution: Evidence from China. Low Carbon Economy, 10, 81101.

https://doi.org/10.4236/lce.2019.103006

Received: August 7, 2019

Accepted: September 23, 2019

Published: September 26, 2019

Copyright (C 2019 by author(s) and Scientific Research Publishing Inc. This work is licensed under the Creative Commons Attribution International License (CC BY 4.0).

http://creativecommons.org/licenses/by/4.0/ (cc) (i)

\begin{abstract}
Air pollution in China is causing significantly negative health effect. The issue is fueled by China's transition to an aging society with a climbing population of elders characterized by great physiological and social vulnerability. Despite the existing investigation on the health effect of air pollution, evidence in China is lack based on the empirical ground, particularly for the elderly. In this study, I examine how air pollution level affects the hospital visits of the elderly in China. Combining data from China Health and Retirement longitudinal Study (CHARLS) and city-level Air Quality Index (AQI) of 2011 and 2013, we conduct individual random effect Probit and fixed-effect Logistic model to eliminate endogeneity from sorting problems and harvesting issues. Results show that increasing air pollution level resulted in negative health effects on the elders, and significantly raised their hospital visits. These effects are more serious for males, aged individuals, low-educated, smoker, and the poor people. The findings indicate the potential benefit of air pollution reduction and provide policy implications for both environmental regulation and health service management.
\end{abstract}

\section{Keywords}

Air Pollution, Health Effect, Aging Society

\section{Introduction}

The health effect of air pollution has become a critical issue in China since the country has been suffering from severe air pollution in the past three decades. The fact of air pollution in China is that only a third of 340 Chinese cities which are monitored to meet China's pollution standards, and it is particularly bad in the belt areas of northeastern China based on Ministry of Environment Protection in 2012. According to the World Bank in 2007, 16 of the world's 20 cities 
with the worst air are in China. In Rhode and Muller's estimation [1], more than 80 percent of Chinese people are regularly exposed to pollution which far exceeds levels deemed safe by the U.S. Environmental Protection Agency (EPA). In addition, the exposure to severe air pollution is also closely related to negative health and social outcomes. Each year, air pollution caused great amount of respiratory diseases, cardiovascular diseases, adverse pregnancy, and even death. The medical expense and air quality improvement induced by air pollution cost a big share of welfare from the government.

Meanwhile, China is transitioning to an aging society, which enforces the government to deal with health effects on the elderly due to air pollution and the induced big medical expenditure. The United Nation pointed out the fact of the elderly in China is that China's aging population will reach $30 \%$ of the total population in 2050. In addition, the elderly also have other disadvantages in defensing the impact from air pollution. First, it is known that the elderly's physiological function is recessed, and they are more vulnerable in their defense and immune system, and consequently more sensitive to poor air quality. Second, the nationwide insurance coverage in China started in 1998, and a certain number of the elderly lack of the health insurance coverage. Third, the education level and income of the elderly in China are usually low ${ }^{1}$, which leads to more concern on the health effect and its protective measurements of bad air quality on the elderly.

In the past, the research on air pollution has mainly focused on short-term and long-term epidemiological studies, and economic or social evaluation of economic/welfare loss. The epidemiological study tried to find the association of short-term or long-term exposure to air pollution and diseases, such as respiratory, cardiovascular, premature delivery, cognitive decline, and even death. The social and economic burden due to air pollution also cause economists' attention, they focused more on the evaluation of the effect of environmental policy, political events, or big events on reducing pollution. In addition, researchers also evaluate the willingness to pay of avoiding the air pollution in the developed countries to provide policy suggestions for the social planner.

Beyond epidemiological study, there is increasing demand in more economic assessment that linked environment degradation and health effects. Researchers have used the cost of illness which measured economic burden of diseases and estimate the maximum amount of money which could be saved if the disease is eradicated, such as Gerking and Stanley [2], Harrington and Portney [3]. However, it is difficult to assess the physical effects of pollution for the reasons for sorting problem and avoidance behavior. These issues will cause measurement error to the pollution exposure. To address these problems, economists applied quasi-experiment techniques, such as finding natural experiments which result in unexpected shocks to environment quality. Examples include changes in en-

${ }^{1}$ The individual average income in this study is about 1000 Chinese Yuan (CNY) each month which is below the $1500 \mathrm{CNY}$ poverty line. And most respondents in our datasets only received the education below the elementary school during the period of World War II. 
vironmental legislation (Greenstone and Hanna [4], Tanaka [5]), economic activity such as economic recession (Chay and Greenstone [6]). Measurement error on air quality also calls attention of using instrumental variables, such as weather indicators (Arceo, Hanna, and Oliva [7]), transportation indicators (Moretti and Neidell [8]). In addition, confounders affect the occurrence of disease but are unknown, and the omission of them could bias the estimated health effect. In the past, researchers have tried to control confounders such as smoking, socioeconomic factors, or other factor (Ebenstein, Fan, and Greentone [9]).

Even though the health effects of air pollution have been widely studied, questions regarding the health effects of air pollution in China have not been widely examined for three reasons. First, the limited air quality data in China restricted the study on the health effects of air pollution in China, especially on a nationwide scale. However, China's air pollution and its health damage turn to be more and more critical to be studied and solved, which calls for a thorough study. Second, existing research on negative health effects caused by air pollution is largely based on the populations exposed to a moderate level of air pollution which are commonly observed in developed countries. However, air pollution concentration in China is about five to ten times higher than developed countries (Greenstone, Hanna, 2011), so current studies from developed countries fail to account for the scope and depth of China's pollution problem. Third, developing and developed countries have different environmental policy enforcements as well as social and economic contexts. Consequently, existing studies from developed countries have limited relevance to China. For example, the enforcement of environmental policies in China is still under query.

With greater concentration levels of air pollution, and different economic and social contexts, China serves as a rare research environment to assess the impacts of air pollution on elderly people. Therefore, this study is intended to precisely fill the gap in the existing literature. And the major contribution to existing literature is that this study will help to enlarge current research to focus on developing country's high concentration air pollution and its health impact, especially on the elderly. In the past, very few literatures of the health and economic effects of air pollution on elderly people were conducted. China is a fast-developing country with high concentration of pollution, and it is transitioning to aging society. It is evident that China serves as a good research object to assess the impacts of air pollution on elderly people at greater concentration levels. This study will reveal facts of air pollution to the social planner and medical system and help them to make policies to react to the air pollution.

In this paper, I examine the hospital visits from China Health and Retirement Longitudinal Study (CHARLS), and its association with Air Pollution Index (AQI). For the data of aging population, CHARLS collected a high quality nationally representative sample of Chinese residents ages 45 and above, which provides the elderly's health and body functioning, medical and insurance, and income information. Accompanied with CHARLS, air quality and specific pol- 
lutants data will be used to estimate health effects of air pollution. The AQI data is collected and reported by local Ministry of Environmental Protection (MEP) branches in China, and then gathered by the head office of MEP in Beijing. Additionally, MEP provided hourly intensities of Nitrogen Oxide $\left(\mathrm{NO}_{2}\right)$, Sulfur Dioxide $\left(\mathrm{SO}_{2}\right)$, Carbon Monoxide (CO), Ozone $\left(\mathrm{O}_{3}\right)$, Particulate Matters $\left(\mathrm{PM}_{2.5}\right.$ and $\mathrm{PM}_{10}$ ) from 1,497 monitors in 160 cities since 2013, which will be applied to study each pollutant's health effect. The results show that there is negative health impact from the AQI and certain pollutants on the elderly people given some individual features, such as age, gender, education level, race and income.

The rest of this paper is organized as follows. Section 2 provides the description of air pollution in China and its health effect. Section 3 focuses on empirical analysis, including data description, summary statistics, the empirical model, and the results. Section 4 proceeds the conclusions.

\section{Air Pollution in China and Its Health Effects}

\subsection{Air Pollution in China}

Air pollution in China has gradually become severe and the causes turned to be complicated in the past three decades. The problem of air pollution in China was first observed in the 1970s with industrial emissions of $\mathrm{SO}_{2}$ and particulate matters. In the 1980s, the acid rain caused by $\mathrm{SO}_{2}$ from coal combustion was detected in major cities in the north of China (Zhang, Liu, Li [10]). According to US Energy Information Administration (2012), China's main energy consumption is coal, which is 4.7 times of the Unites States, and almost 60 times that of UK's, covering iron, steel, and cement industries. Since the 1990s, the rapid increase in the number of motor vehicles in urban China leads to the air pollution changed from conventional coal combustion to the mixed coal combustion/motor vehicle emission type of pollution, which led to substantial degradation of air quality, especially in the urban areas. Beyond coal combustion and motor vehicle emission, another two important pollution sources in China are the dust generated by urban planning and constructions due to the fast urbanization, and the waste generated by municipal and large population.

Despite the emission from industry and vehicles, there are several other factors need to be considered in affecting the pollution. First, the meteorology, not only wind speed, but also relative humidity, cloudiness, temperature inversions affect the air quality. For example, China's air pollution more happened in northern cities in the winter which requires stable atmosphere conditions, such as low wind speeds and weak vertical atmosphere mixing, which allows pollutants to accumulate and react with each other (Wang, Dickinson, Su, Zhou, and Wang [11]). Meanwhile, the accumulated atmosphere may absorb solar radiation and warms the atmospheric aloft and reduces air movement and trap pollutants. In addition, factors such as geographic feature also play important role in air quality, especially for some northern provinces or cities, such as Beijing-Hebei-Tianjin region which is surrounded by mountains which block the diffusion 
of the haze.

Even though China is gradually shifting to non-fossil energy sources by applying clean energy to reduce air pollution, achieving the goal will have some political or technical difficulties. For example, the transition is not only expensive but also involves technical challenges. Moreover, the technical challenges are also compounded by political difficulties. The reduction in pollution emissions depends on the ability of the political system to find alternative sources of economic development and provide financial path for state-owned coal-based industry and power plants to close or reduce output, which requires decentralized decision-making in China and reducing the bureaucratic power of state-owned industries.

Beyond discussing the sources and causes of pollutants, the concentration of pollution changes greatly in China as well. Beyond $\mathrm{SO}_{2}, \mathrm{NO}_{\mathrm{x}}$, particulate matters $\left(\mathrm{PM}_{10}\right.$ and $\left.\mathrm{PM}_{2.5}\right)$ have appeared to surge in recent years, which were mainly created by car emissions and industry. Another important pollutant which is harmful in causing respiratory disease is ozone, and between 2005 and 2010, China's $\mathrm{NO}_{\mathrm{x}}$ emissions went up 21\%, and the rise in emissions has led to $7 \%$ increase in ozone in China, indicated by Quartz in 2015. To give a better description of the air pollutants and its sources, the air pollutants and their major sources, and the health effects of specific pollutant are listed in Table 1.

\subsection{Health Effects of Air Pollution}

It has been proved that air pollution is a major environmental risk to health. The number of hospital visits for respiratory diseases, stroke, and heart disease has increased in China recent years, which called the public's attention on the health effects of air pollution. In the short-term, the air pollution on a day-to-day basis

Table 1. Main air pollutants, the sources, and their health effects.

\begin{tabular}{|c|c|c|}
\hline Pollutant & Source & Human Health Effect \\
\hline \multirow[t]{3}{*}{$\begin{array}{l}\text { Particulate } \\
\text { Matters }\end{array}$} & Internal combustion engines; industry; mining & Lung disease/cancer \\
\hline & $\begin{array}{l}\text { Motor vehicles; burning wood; cigarette smoke; } \\
\text { bushfires }\end{array}$ & heart disease; asthma \\
\hline & & Lung/respiratory disease \\
\hline \multirow{2}{*}{$\mathrm{NO}_{2}$} & \multirow{2}{*}{ Motor vehicles; other combustion } & Asthma; increased mortality \\
\hline & & Increased hospital admission \\
\hline \multirow[t]{2}{*}{$\mathrm{CO}$} & Motor vehicles; industry & Increased mortality \\
\hline & burning of coal, oil, and wood; waste incineration & \\
\hline \multirow{2}{*}{$\mathrm{SO}_{2}$} & \multirow{2}{*}{ Fossil fuel combustion; industry } & Bronchoconstriction; asthma; \\
\hline & & Increased hospital admission \\
\hline \multirow{3}{*}{$\mathrm{O}_{3}$} & Reaction between oxides of nitrogen and volatile & \\
\hline & organic compounds & Lung diseases, asthma \\
\hline & Industry; Motor Vehicle exhaust; gasoline vapors & \\
\hline
\end{tabular}

Source: US Environmental Protection Agency. 
may cause some noticeable symptoms: for the overall population, they will experience irritative nose, throat, eyes, and cough. In some cases, poor air quality will cause headaches, dizziness, and nausea. For the sensitive adult or children with lung or heart conditions, they are at risk of experiencing illness and needing treatment. For instance, people with asthma may notice that they need to increase their use of inhaled reviler on the days when air pollution is severe. Especially for the elderly, they are more likely to suffer from heart and lung conditions than young people, such as breathing difficulties, and higher likelihood of heart diseases. Long-term effects of air pollution can last for years or the entire lifetime. Beyond respiratory and cardiovascular diseases, long-term exposure to poor quality air will also damage people's nerves, brain and other organs, and even causes birth defects, by National Geographic Society's report in 2016. In addition, other long-term health effects of air pollution includes that American Heart Association in 2015 indicated that air pollution also plays a role in high blood pressure and diabetes. American Psychological Association in 2012 has pointed out that the air pollution will also cause damage in children's cognitive ability, increase adults' risk of cognitive decline and possibly even contribute to depression. In Table 2, the health effects of air pollution on sensitive group of people are summarized. It is shown that: 1) air pollution will cause worsen symptoms to people with respiratory diseases, such as asthma and lung disease; 2) for people with cardiovascular disease, air pollution causes palpitations, chest pain, and breath shortness; 3) its effect on pregnant women and children includes reduced birthweight, preterm birth, continuous infection, and lung diseases; 4) the air pollution affects elderly people's health by heart disease, stroke, lung disease, and asthma.

\section{Empirical Analysis}

\subsection{Data}

In this paper, the Air Quality Index (AQI) is applied to indicate the air quality in China. Since June 2000, the Ministry of Environmental Protection (MEP) of China has published daily AQI for capital cities, districts (such as Beijing, Shanghai), and middle and some small-sized cities over mainland of China to

Table 2. Health effects of air pollution on sensitive people.

\begin{tabular}{cc}
\hline Group of People & Human Health Effect \\
\hline $\begin{array}{c}\text { People with asthma } \\
\text { People with lung disease } \\
\text { People with cardiovascular disease }\end{array}$ & Worsen symptoms, or trigger asthma attacks \\
Pregnant women & Cause palpitations, chest pain, shortness of breath \\
Children & Reduced birth weight, preterm birth \\
The elderly & Frequent respiratory infections, effects on the lung \\
\hline
\end{tabular}

Source: US Environmental Protection Agency. 
measure the air quality. The mechanism of reporting AQI is, local MEP branches set the monitors around a city and the air quality data is collected and reported to the head office of MEP in Beijing. The calculation principle of AQI is, the MEP collects the intensities of $\mathrm{NO}_{2}, \mathrm{SO}_{2}, \mathrm{O}_{3}$ and $\mathrm{PM}_{10}$, and the overall AQI is the maximum one of these specific pollutant indexs. To better understand AQI and its health implications, MEP categorized AQI into 6 levels, which is shown in Table 3.

However, AQI has limitation on describing health effects since it is a summary of concentrations of pollutants, and specific pollutants have different health effects, which are also associated with the seasonal variations, such as $\mathrm{O}_{3}$ usually has higher value in summer. To better capture impacts of different pollutants, this study includes major pollutants, such as $\mathrm{SO}_{2}, \mathrm{NO}_{2}, \mathrm{CO}, \mathrm{O}_{3}, \mathrm{PM}_{2.5}$, and $\mathrm{PM}_{10}$ in year 2013 from MEP to estimate health effects of each pollutant on elderly people's health. Based on the World Health Organization in 2016, the criterion of specific pollutants is indicated in Table 4, including particulate matters, $\mathrm{NO}_{2}, \mathrm{CO}, \mathrm{SO}_{2}$, and $\mathrm{O}_{3}$.

From 2011, Peking University initiated the China Health and Retirement Longitudinal Survey (CHARLS) to collect a high quality nationally representative

Table 3. Ministry of environmental protection's categories of AQI.

\begin{tabular}{|c|c|c|c|}
\hline AQI & Level & Condition & Health Implications \\
\hline $0-50$ & Green & Excellent & No Health Implications. \\
\hline $51-100$ & Yellow & Good & Few hypersensitive individuals should reduce outdoor exercise. \\
\hline $101-150$ & Orange & Lightly Polluted & $\begin{array}{l}\text { Slight irritations may occur, individuals with breathing or heart problems should reduce } \\
\text { outdoor exercise. }\end{array}$ \\
\hline $201-300$ & Purple & Heavily Polluted & $\begin{array}{l}\text { Healthy people will be noticeably affected. People with breathing or heart problems will } \\
\text { experience reduced endurance in activities. These individuals and elders should remain } \\
\text { indoors and restrict activities. }\end{array}$ \\
\hline $300+$ & Maroon & Severely Polulted & $\begin{array}{l}\text { Healthy people will experience reduced endurance in activities. There may be strong } \\
\text { irritations and symptoms and may trigger other illnesses. Elders and the sick should remain } \\
\text { indoors and avoid exercise. Healthy individuals should avoid outdoor activities. }\end{array}$ \\
\hline
\end{tabular}

Source: Ministry of Environmental Protection of China.

Table 4. The criterion of specific pollutants (by Region).

\begin{tabular}{cc}
\hline Pollutants & Suggested Level \\
\hline $\mathrm{PM}_{2.5}$ & $10 \mu \mathrm{g} / \mathrm{m}^{3}$ (Annual Average $) / 25 \mu \mathrm{g} / \mathrm{m}^{3}$ (24-hour Average) \\
$\mathrm{PM}_{10}$ & $20 \mu \mathrm{g} / \mathrm{m}^{3}$ (Annual Average $) / 50 \mu \mathrm{g} / \mathrm{m}^{3}$ (24-hour Average) \\
$\mathrm{O}_{3}$ & $100 \mu \mathrm{g} / \mathrm{m}^{3}$ (8-hour Average) \\
$\mathrm{NO}_{2}$ & $40 \mu \mathrm{g} / \mathrm{m}^{3}$ (Annual Average $) / 200 \mu \mathrm{g} / \mathrm{m}^{3}$ (1-hour Average) \\
$\mathrm{SO}_{2}$ & $20 \mu \mathrm{g} / \mathrm{m}^{3}(24$-hour Average $) / 500 \mu \mathrm{g} / \mathrm{m}^{3}$ (10-minute Average) \\
\hline
\end{tabular}

Source: World Health Organization, 2016. 
sample of Chinese residents aged 45 and above, which includes about 10,000 households and 17,500 individuals in 28 provinces, 150 counties/districts and 450 villages/resident committees all over China. In CHARLS, the respondents were interviewed once in certain month starting from year 2011 (Most of them are interviewed in the summer and fall), and they are followed every other year with the same questions. The information from CHARLS can be used in this study includes information of the respondents' demographics, health status and functioning, health care and insurance, income and consumption. In this paper, the dependent variable will be total number of hospital admission for respiratory, cardiovascular, and some other diseases which are related to the air pollution. Additionally, respondent's individual characteristics such as monthly income, marriage status, smoking status, race, and education level information were included. This information will be used to control for specific variation between individuals.

In this study, I will use the data for 54 cities from 24 provinces which are listed in Table 5. In addition, study cities were graphically shown in Figure 1. However, in the northwest and southwest of China, there is only about $10 \%$ of the population because of the existence of deserts and plateau, which was not covered in CHARLS and this study.

Before establishing the empirical model, the summary statistics of all the variables are listed in Table 6 . From the table, the monthly average possibility for

Table 5. List of study region, province/district, and city ( ${ }^{*}$ Means District).

\begin{tabular}{|c|c|c|}
\hline Region & Province/District & city \\
\hline & Beijing $^{*}$,Shanghai ${ }^{\star}$, Tianjin $^{*}$ & - \\
\hline & Hebei & Baoding, Shijiazhuang \\
\hline & Jiangsu & Suzhou, Yangzhou, Lianyungang, Xuzhou \\
\hline \multirow[t]{4}{*}{ East } & Zhejiang & Huzhou, Ningbo, Hangzhou, Jiaxing, Taizhou \\
\hline & Shandong & Qingdao, Jinan, Zaozhuang, Weihai, Weifang \\
\hline & Guangdong & Foshan, Shenzhen, Guangzhou \\
\hline & Shanxi & Yangquan, Linfen \\
\hline \multirow[t]{6}{*}{ Middle } & Jiangxi & Nanchang, Jiujiang \\
\hline & Henan & Anyang, Luoyang, Zhengzhou, Pingdingshan, Jiaozuo \\
\hline & Hunan & Yueyang, Changsha, Changde \\
\hline & Chongqing ${ }^{\star}$ & - \\
\hline & Sichuan & Chengdu, Nanchong, Yibin, Mianyang \\
\hline & Yunnan, Gansu & Kunming, Lanzhou \\
\hline \multirow[t]{4}{*}{ West } & Shaanxi & Weinan, Baoji \\
\hline & Neimenggu & Hohhot, Chifeng \\
\hline & Guangxi & Guilin, Nanning \\
\hline & Liaoning & Benxi, Anshan, Dalian, Jinzhou \\
\hline \multirow[t]{2}{*}{ Northeast } & Jilin & Jilin \\
\hline & Heilongjiang & Qiqihar, Harbin \\
\hline
\end{tabular}

Source: author's summary. 


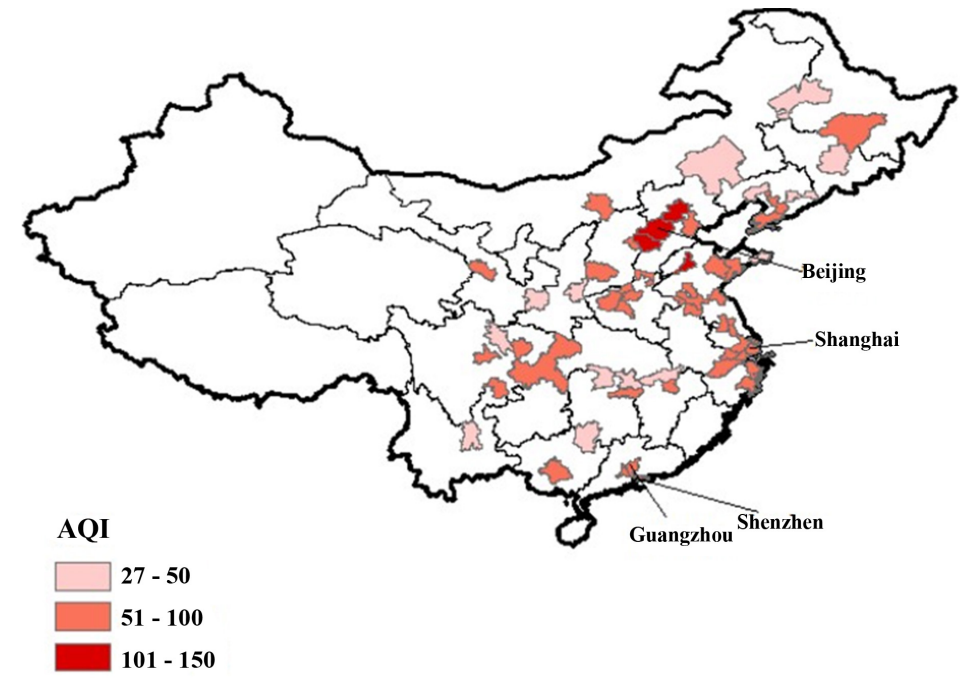

Figure 1. The intensity of annual average AQI and research cities. Source: author's estimate.

Table 6. Summary statistics and explanation of variables.

\begin{tabular}{|c|c|c|c|c|c|}
\hline Variable & Explanation & Mean & Min & Max & S.D. \\
\hline \multicolumn{6}{|c|}{ Panel (a): Hospital visit } \\
\hline Hospital Visits & $\begin{array}{l}\text { Whether hospital visits happened in } \\
\text { last month }\end{array}$ & 0.20 & 0 & 1 & 0.40 \\
\hline \multicolumn{6}{|c|}{$\begin{array}{l}\text { Panel (b): AQI and } \\
\text { pollutants }\end{array}$} \\
\hline AQI & Annual average AQI & 69.78 & 9.43 & 212.60 & 27.87 \\
\hline $\mathrm{SO}_{2}$ & Annual average of $\mathrm{SO}_{2}\left(\mu \mathrm{g} / \mathrm{m}^{3}\right)$ & 26.98 & 6.97 & 109.29 & 18.20 \\
\hline $\mathrm{NO}_{2}$ & Annual average of $\mathrm{NO}_{2}\left(\mu \mathrm{g} / \mathrm{m}^{3}\right)$ & 38.10 & 14.10 & 87.32 & 12.74 \\
\hline $\mathrm{CO}$ & Annual average of $\mathrm{CO}\left(\mu \mathrm{g} / \mathrm{m}^{3}\right)$ & 1.12 & 0.50 & 5.05 & 0.60 \\
\hline $\mathrm{O}_{3}$ & Annual average of $\mathrm{O}_{3}\left(\mu \mathrm{g} / \mathrm{m}^{3}\right)$ & 121.44 & 47.67 & 194.14 & 35.50 \\
\hline $\mathrm{PM}_{2.5}$ & Annual average of $\mathrm{PM}_{2.5}\left(\mu \mathrm{g} / \mathrm{m}^{3}\right)$ & 59.51 & 14 & 185.40 & 34.42 \\
\hline $\mathrm{PM}_{10}$ & Annual average of $\mathrm{PM}_{10}\left(\mu \mathrm{g} / \mathrm{m}^{3}\right)$ & 101.00 & 32.19 & 353.45 & 56.09 \\
\hline \multicolumn{6}{|c|}{$\begin{array}{l}\text { Panel (c): Individual } \\
\text { characteristics }\end{array}$} \\
\hline Age & Respondent's age & 59.84 & 29 & 97 & 9.81 \\
\hline Income & Annual income (CNY) & $15,109.41$ & 0 & 230,000 & $19,562.45$ \\
\hline Male & Gender (1: Male) & 0.48 & 0 & 1 & 0.50 \\
\hline Race & Han (1) or minorities $(0)$ & 0.963 & 0 & 1 & 0.19 \\
\hline Marriage & Married (1) or other (0) & 0.842 & 0 & 1 & 0.365 \\
\hline Education & Education status ${ }^{a}$ & 3.77 & 1 & 10 & 1.95 \\
\hline Smoking & Smoking status (1: Smoking) & 0.293 & 0 & 1 & 0.455 \\
\hline Urban & Living area (1: Living in the urban) & 0.489 & 0 & 1 & 0.499 \\
\hline
\end{tabular}

${ }^{a}$ For instance, 1: No formal education illiterate; 4: Elementary School; 10: Post-graduate, Masters degree. Source: author's estimate. 
hospital visit is about $20 \%$. The age of respondent ranges from 29 to 97 years old, and the average age is about 60 . For individual characteristics, it is easy to find that over $96 \%$ respondents are in the race of $\mathrm{Han}^{2}$; around $80 \%$ of the respondent are married, and the gender is evenly distributed. However, the education level on average is below the elementary school, and very few of the respondents have received the four-year college education (less than 5\%). Among the respondents who provided the information about their smoking status, over $70 \%$ are still smoking. In addition, about $48 \%$ of the respondents are living in the urban area. However, the average annual income is around 15,109 CNY, which is below the average per capita disposable income 24,565 CNY in 2012.

Based on our air quality data and specific pollutant data, we can find that the annual average value of AQI is about 69 (close to light pollution level) in these two years, and the maximum value has reached 213 (Heavily Polluted). Specifically, there are about 100 days in 2011 or 2013 have reached lightly polluted level, 12 moderately polluted days, and 7 heavily polluted day based on MEP's criterion. In addition, the AQI indicates a seasonal variation that in the winter it is higher and relatively low during the summer, which is shown in Figure 2. Among specific pollutants, the average values of all the pollutants exceeds the criterion made by World Health Organization except $\mathrm{NO}_{2}$ in the year 2013 which is shown in Table 4.

Even though AQI has been observed the high value in the winter and low value in the summer, which is not the case for other pollutants. To better capture the seasonal variation of specific pollutants, I firstly use Figure 3 to indicate their monthly values by regions. From Figure 3, we find that most pollutants have similar seasonal variation with $\mathrm{AQI}$ except $\mathrm{O}_{3}$. Contrary to other pollutants, $\mathrm{O}_{3}$ increased in the summer and decreased in the winter. The reason for $\mathrm{O}_{3}$ 's increase in summer is that $\mathrm{O}_{3}$ is a highly unstable and reactive compound. It tends to react with other components within its formation moments, and it is forming faster than it is self-destructing during warm weather. The warm temperature accelerates atmospheric reaction which produces ozone. For example, ozone occurs more between May and September, and the highest daily concentrations generally occur between mid and late afternoon. To indicate the relationship between AQI and specific pollutants, in Table 7 and Table 8, there are very high

Table 7. The correlation between AQI and specific pollutants (by Region).

\begin{tabular}{ccccccc}
\hline & $\mathrm{SO}_{2}$ & $\mathrm{NO}_{2}$ & $\mathrm{CO}$ & $\mathrm{O}_{3}$ & $\mathrm{PM}_{2.5}$ & $\mathrm{PM}_{10}$ \\
\hline East & 0.92 & 0.96 & 0.95 & -0.450 & 0.996 & 0.974 \\
Middle & 0.93 & 0.84 & 0.89 & 0.091 & 0.999 & 0.992 \\
West & 0.95 & 0.58 & 0.87 & -0.167 & 0.997 & 0.978 \\
Northeast & 0.92 & 0.86 & 0.97 & -0.536 & 0.993 & 0.992 \\
\hline
\end{tabular}

Source: author's estimate.

${ }^{2}$ In CHARLS, the race reported includes Han, Hui, Zhuang, Yi, Tibet, Miao, Mongol, and other, and Han is the biggest race in China. 
Table 8. The covariance between AQI and specific pollutants (by Region).

\begin{tabular}{ccccccc}
\hline & $\mathrm{SO}_{2}$ & $\mathrm{NO}_{2}$ & $\mathrm{CO}$ & $\mathrm{O}_{3}$ & $\mathrm{PM}_{2.5}$ & $\mathrm{PM}_{10}$ \\
\hline East & 268.105 & 416.105 & 12.079 & -260.345 & 676.051 & 645.352 \\
Middle & 728.188 & 376.714 & 17.738 & 49.430 & 1191.503 & 1530.266 \\
West & 146.709 & 72.087 & 4.548 & -334.338 & 396.181 & 603.900 \\
Northeast & 986.944 & 353.657 & 10.759 & -576.087 & 1252.324 & 1478.264 \\
\hline
\end{tabular}

Source: author's estimate.
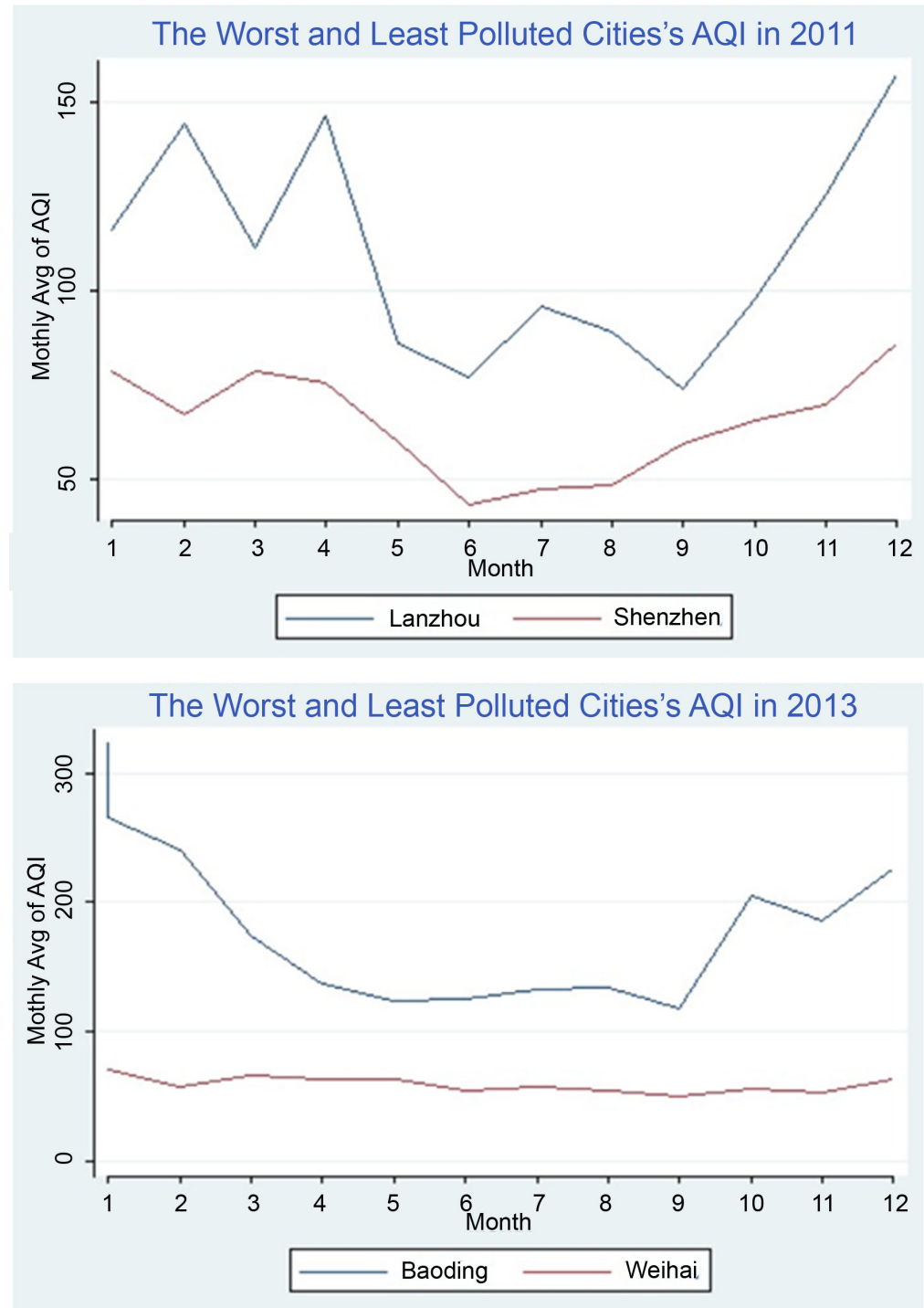

Figure 2. AQI Distribution for the Most and Least Polluted Cities (2011 \& 2013). Source: author's estimate.

correlations (close to 1 ) and covariances between AQI and pollutants, such as $\mathrm{SO}_{2}, \mathrm{NO}_{2}, \mathrm{CO}$, and particulate matters. However, there is negative relationship between $\mathrm{O}_{3}$ and other pollutants, and in the covariance, which supports the phenomenon that the seasonal variation of $\mathrm{O}_{3}$ is different from other pollutants. 
Monthly Average of $\mathrm{SO}_{2}$ in 2013

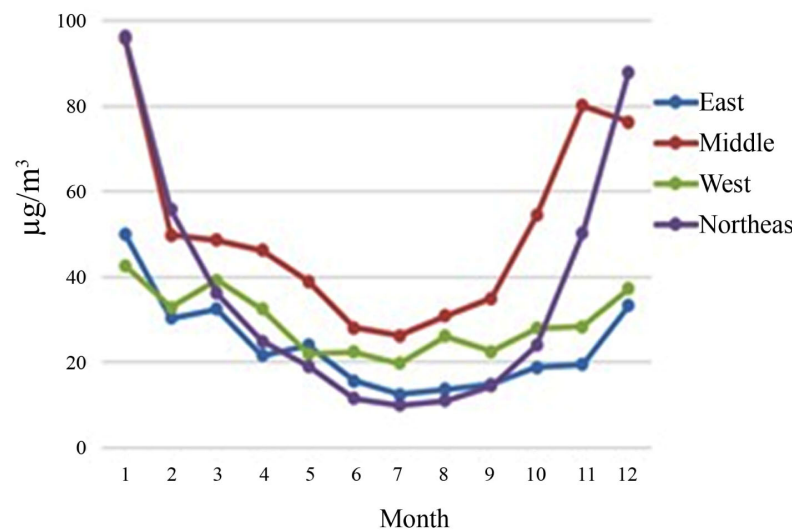

Monthly Average of $O_{2}$ in 2013

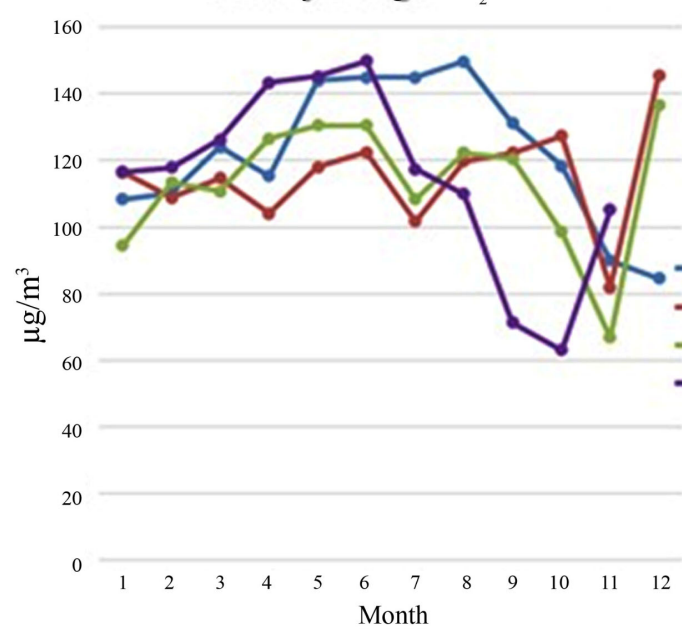

Monthly Average of $P M_{2.5}$ in 2013

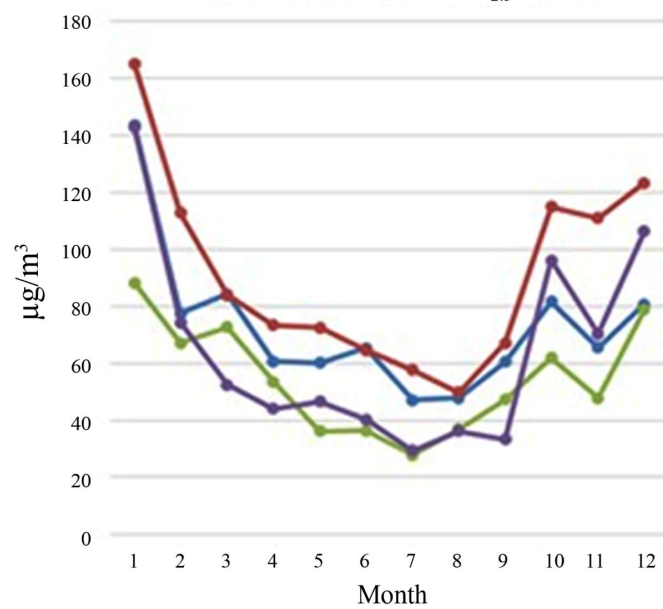

Monthly Average of $\mathrm{NO}_{2}$ in 2013

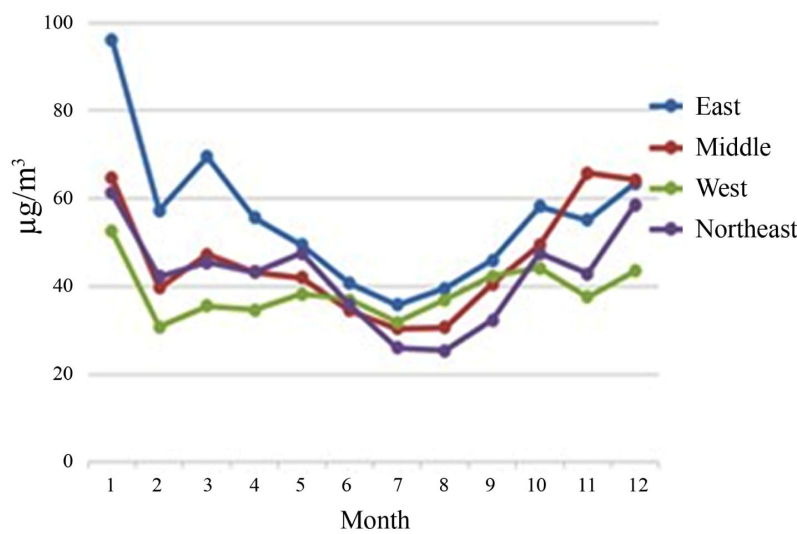

Monthly Average of $\mathrm{CO}_{2}$ in 2013

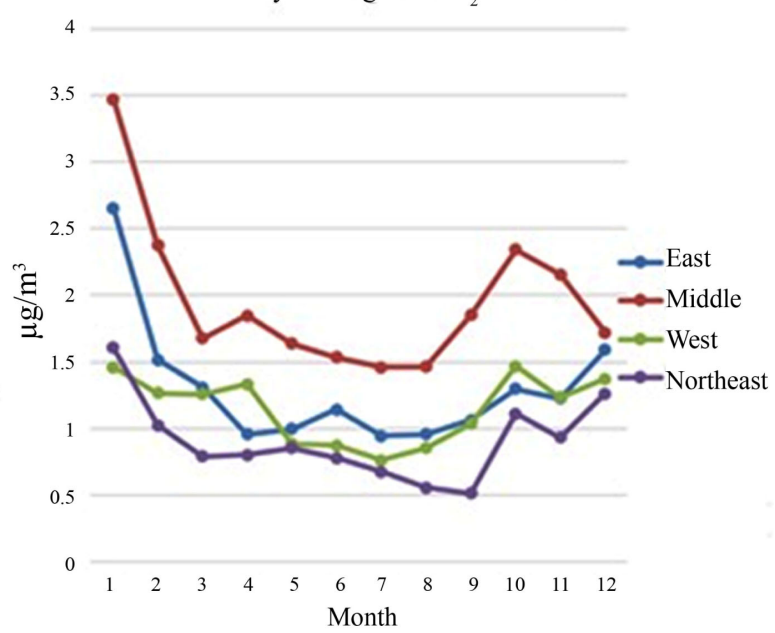

Monthly Average of $P M_{10}$ in 2013$$
300
$$

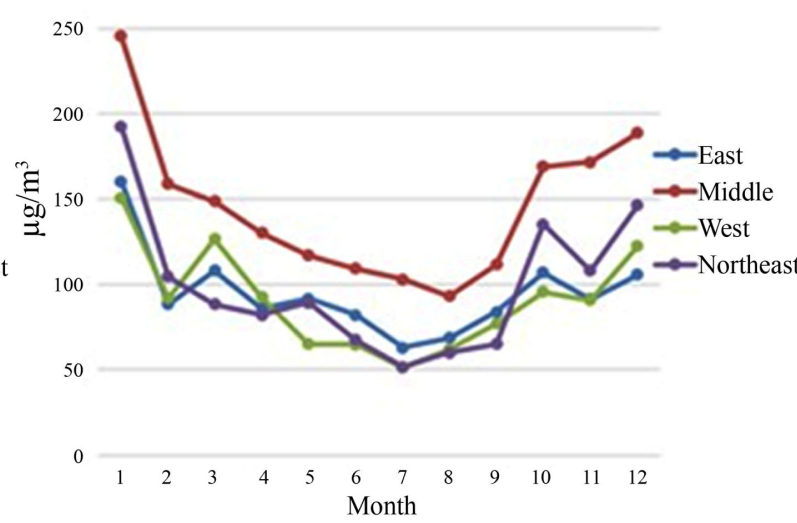

Figure 3. Specific Pollutant Distribution in 2013. Source: author's estimate.

The comparison between winter and summer for different pollutants is also shown in Figure 4 by the spider graph. 


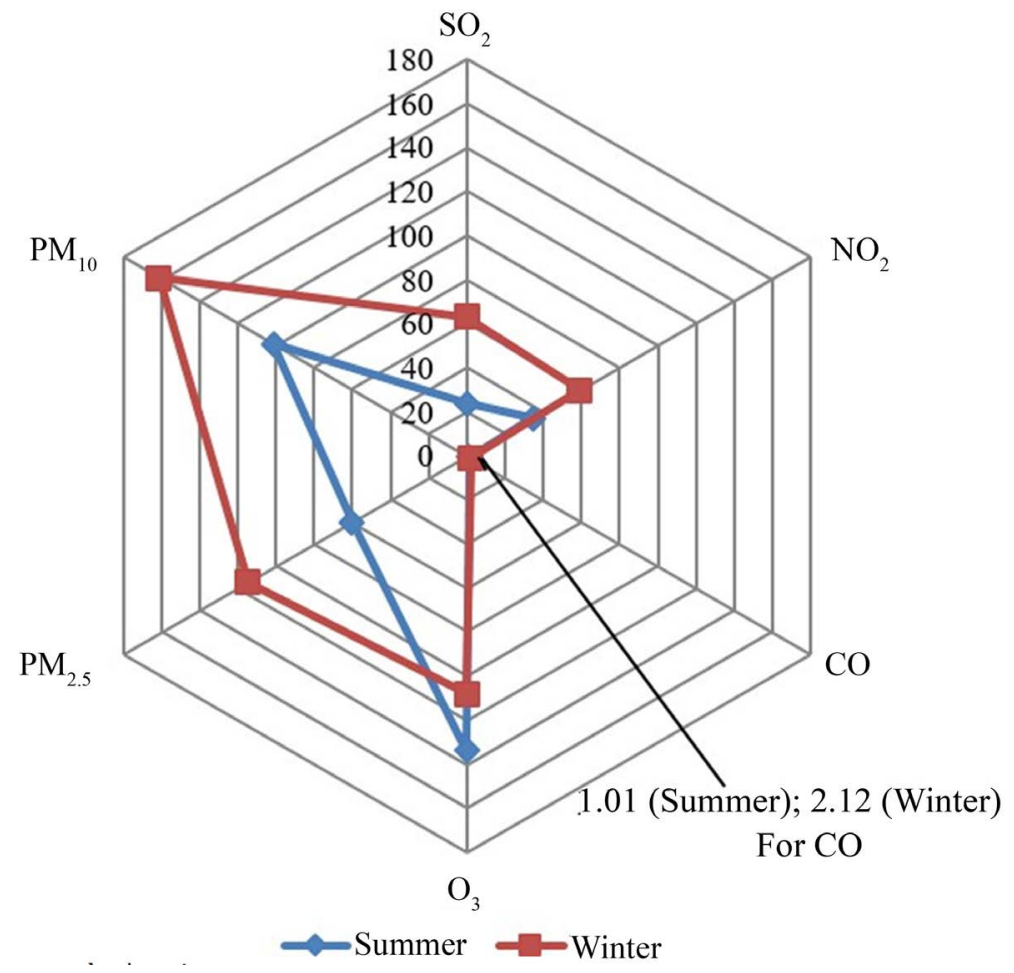

Figure 4. The Seasonal Variation of Pollutants (2013). Source: author's estimate.

In reviewing the economic literature, the sorting problem in which people vote by their feet to choose residential locations based on the features of locations can also be found in this study. Since the medical resources in China are allocated unevenly, so people in certain area will have more chance to get medical treatment even if they are also living heavily polluted areas. Thus, the Jackknife estimation was used to find out the cities in our study which may have sorting problem and affect the empirical results, which is shown in Figure 5. From it, it is easily found that cities such as Beijing, Baoding, Chongqing and Shijiazhuang have the relatively high or low dfbeta index, which will allow us to visualize how influential of some cities are compared with the rest in the regression of hospital visit and air quality. Thus, in this study, these cities are excluded out from the research sample of the regression.

\subsection{Empirical Model}

Based on Wooldridge [12], I consider to use the random effect Probit model and the fixed effect Logistic model clustered in the city level to study the effect of air pollution on elderly people's hospital visit, and the fixed effect is likely to control for the regional and time-invariant characteristics. To control the bias of confounders on estimated result, I add socioeconomic variables into the model (Ebenstein, Fan, and Greenstone, 2015). In CHARLS, the responders reply that whether they had hospital visits in the last month, which is the dependent variable in the model. The independent variable will be the AQI or index for specific pollutants, and their interaction terms with the categorical variables such as age, 


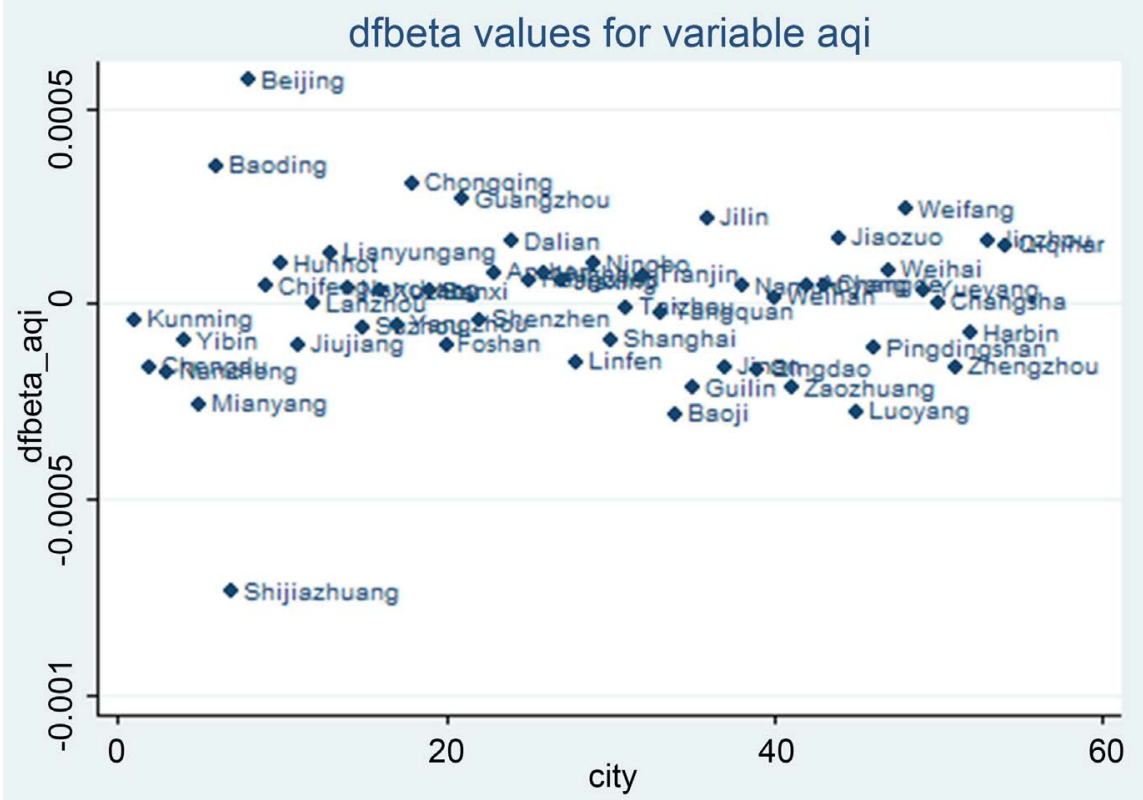

Figure 5. Dfbeta of Cities. Source: author's estimate.

race, gender, income, education level, marriage or smoking status, living in urban or rural.

The random Probit model begins with:

$$
y_{i t}=\alpha+\alpha_{1} \mathrm{AQI}_{i t} / P_{i t}+\alpha_{2} \mathrm{AQI}_{i t} * X_{i t}+\mu_{i t}
$$

where $y_{i t}$ is the dummy variable denoting that respondent $i$ visited the doctor at time $t$ or not. AQI ${ }_{i t} / P_{i t}$ is the average AQI/specific pollutant in location $i$ at time $\mathrm{t}$; $X_{i t}$ is the dummy variable indicating socioeconomic status such as age, gender, marriage status, race, education level, income, and smoking status at time $t ; \mu_{i t}$ is the error term.

The fixed effect Logistic model is:

$$
y_{i t}=\beta_{i}+\beta_{1} \mathrm{AQI}_{i t} / P_{i t}+\beta_{2} \mathrm{AQI}_{i t} * X_{i t}+s_{i t}
$$

where $y_{i t}$ is the dummy variable denoting that respondent $i$ visited the doctor at time $t$ or not. AQI ${ }_{i t} / P_{i t}$ is the average AQI/specific pollutant in location $i$ at time $\mathrm{t}$; $X_{i t}$ is the dummy variable indicating socioeconomic status such as age, gender, marriage status, race, education level, income, and smoking status at time $t ; s_{i t}$ is the error term. Since the air quality of one city will be independent from another city, the model is clustered in the city level.

\subsection{Empirical Results}

Since air pollution has different influence on the groups of people, the respondents CHARLS were categorized into groups by age, education level, gender, marriage status, race, smoking status, income, and living areas. This study examines the effects of AQI and specific pollutants on hospital visits by these categories. The result is shown in Tables 9-14. Tables 9-12 indicate the relationship between AQI and hospital visits with different socioeconomic features. 
Table 9. Marginal health effects of AQI and pollutants by age group.

\begin{tabular}{|c|c|c|c|c|c|c|}
\hline VARIABLES & visit & visit & visit & visit & visit & visit \\
\hline AQI & 0.0002 & 0.0005 & 0.0007 & 0.0009 & $0.0017^{*}$ & $0.0018^{* *}$ \\
\hline AQI ${ }^{*}$ Age $50+$ AQI $^{*}$ Age $55+$ & $\begin{array}{c}(0.001) \\
0.002^{* * *}(0.001)\end{array}$ & $\begin{array}{c}(0.001) \\
0.0021^{* * *}\end{array}$ & $(0.001)$ & $(0.001)$ & $(0.001)$ & $(0.001)$ \\
\hline $\mathrm{AQI}^{*}$ Age $60+$ & & $(0.001)$ & $0.0024^{\star * *}$ & & & \\
\hline AQI*Age $65+^{*}$ & & & $(0.000)$ & $0.0030^{* * *}$ & & \\
\hline $\mathrm{AQI}^{*}$ Age $70+$ & & & & $(0.001)$ & $0.0015^{\star *}$ & \\
\hline $\mathrm{AQI}^{\star}$ Age $75+$ & & & & & $(0.001)$ & $0.0018^{\star *}$ \\
\hline \multirow{3}{*}{ Constant } & & & & & & $(0.001)$ \\
\hline & $-1.16^{\star * *}$ & $-1.166^{\star * \star}$ & $-1.1616^{* * *}$ & $-1.1585^{\star * *}$ & $-1.1709^{* * *}$ & $-1.1703^{\star \star \star}$ \\
\hline & $(0.069)$ & $(0.069)$ & $(0.069)$ & $(0.069)$ & $(0.069)$ & $(0.069)$ \\
\hline Observations & 10,694 & 10,694 & 10,694 & 10,694 & 10,694 & 10,694 \\
\hline Number of ID & 5366 & 5366 & 5366 & 5366 & 5366 & 5366 \\
\hline
\end{tabular}

${ }^{* * *} \mathrm{p}<0.01,{ }^{* *} \mathrm{p}<0.05,{ }^{*} \mathrm{p}<0.1$. Source: author's estimate.

Table 10. Marginal health effects of AQI and pollutants by education level.

\begin{tabular}{cccc}
\hline VARIABLES & visit & visit & visit \\
\hline AQI & 0.0011 & 0.0009 & 0.0007 \\
& $(0.001)$ & $(0.001)$ & $(0.001)$ \\
AQI ${ }^{*}$ No Primary School & $0.0019^{* * *}$ & & \\
AQI*Elementary School & $(0.001)$ & & \\
& & $0.002^{* * *}$ & \\
AQI*High School & & $(0.000)$ & $0.0013^{* *}$ \\
& & & $(0.001)$ \\
Constant & $-1.160^{* * *}$ & $-1.1644^{* * *}$ & $-1.165^{* * *}$ \\
& $(0.065)$ & $(0.065)$ & $(0.065)$ \\
Observations & 10,806 & 10,806 & 10,806 \\
Number of ID & 5437 & 5437 & 5437 \\
\hline
\end{tabular}

${ }^{* * *} \mathrm{p}<0.01,{ }^{* *} \mathrm{p}<0.05,{ }^{*} \mathrm{p}<0.1$. Source: author's estimate.

Table 11. Marginal health effects of AQI and Pollutants by gender, smoking status, marriage status, race.

\begin{tabular}{|c|c|c|c|c|c|c|}
\hline VARIABLES & visit & visit & visit & visit & visit & visit \\
\hline AQI & $0.0030^{* * *}$ & 0.0012 & $0.0030^{* * *}$ & $0.0049^{* * *}$ & -0.002 & -0.002 \\
\hline $\mathrm{AQI}^{\star}$ Male AQI ${ }^{\star}$ Smoke & $\begin{array}{c}(0.001) \\
0.0027^{\star * *} \\
(0.000)\end{array}$ & $\begin{array}{c}(0.002) \\
0.0045^{\star * *}\end{array}$ & $(0.001)$ & $(0.002)$ & $(0.004)$ & $(0.004)$ \\
\hline $\mathrm{AQI}^{\star}$ Marriage & & $(0.001)$ & $-0.0014^{\star *}$ & & & \\
\hline AQIRace (Han) & & & $(0.001)$ & $-0.0031^{\star *}$ & & \\
\hline $\begin{array}{c}\mathrm{AQI}^{*} \text { Annual Income }< \\
10,000 \mathrm{CNY}\end{array}$ & & & & $(0.001)$ & $\begin{array}{l}0.0035^{*} \\
(0.002)\end{array}$ & \\
\hline
\end{tabular}


B. Y. Liu

\section{Continued}

\begin{tabular}{|c|c|c|c|c|c|c|}
\hline $\begin{array}{c}\text { AQI }^{*} \text { Annual Income }< \\
20,000 \mathrm{CNY}\end{array}$ & & & & & & $\begin{array}{c}0.002 \\
(0.002)\end{array}$ \\
\hline \multirow[t]{2}{*}{ Constant } & $-1.1523^{* * *}$ & $-1.2885^{* * *}$ & $-1.159^{* * *}$ & $-1.1714^{\star * *}$ & $-1.2530^{\star * *}$ & $-1.2400^{\star * *}$ \\
\hline & $(0.065)$ & $(0.169)$ & $(0.065)$ & $(0.065)$ & $(0.349)$ & $(0.361)$ \\
\hline Observations & 10,828 & 2,866 & 10,834 & 10,835 & 828 & 828 \\
\hline Number of ID & 5437 & 2208 & 5437 & 5437 & 728 & 728 \\
\hline
\end{tabular}

${ }^{* * *} \mathrm{p}<0.01,{ }^{* *} \mathrm{p}<0.05,{ }^{*} \mathrm{p}<0.1$. Source: author's estimate.

Table 12. Odds ratio of AQI and pollutants by living area.

\begin{tabular}{cc}
\hline VARIABLES & Odds Ratio (Hospital Visit) \\
\hline AQI & 0.9997 \\
& $(0.002)$ \\
Urban & $0.5318^{* *}$ \\
& $(0.149)$ \\
AQI*Urban & $1.0081^{* *}$ \\
& $(0.003)$ \\
Constant & $0.2361^{* * *}$ \\
Observations & $(0.052)$ \\
Number of area & 10835 \\
\end{tabular}

Robust se in parentheses. ${ }^{* *} \mathrm{p}<0.01,{ }^{* *} \mathrm{p}<0.05,{ }^{*} \mathrm{p}<0.1$. Source: author's estimate.

Table 13. Odds ratio of pollutants by age.

\begin{tabular}{|c|c|c|c|}
\hline VARIABLES & Odds ratio & Odds ratio & Odds ratio \\
\hline $\mathrm{SO}_{2}$ & $\begin{array}{l}0.9609^{* *} \\
(0.016)\end{array}$ & & \\
\hline Age $50+$ & $\begin{array}{l}0.6364 \\
(0.183)\end{array}$ & & $\begin{array}{c}0.508 \\
(0.226)\end{array}$ \\
\hline $\mathrm{SO}_{2}{ }^{*}$ Age $50+$ & $\begin{array}{l}1.0280^{\star *} \\
(-0.013)\end{array}$ & & \\
\hline $\mathrm{NO}_{2}$ & & $\begin{array}{l}0.9919 \\
(0.009)\end{array}$ & \\
\hline Age $60+$ & & $\begin{array}{l}0.6392 \\
(0.215)\end{array}$ & \\
\hline $\mathrm{NO}_{2}{ }^{\star}$ Age $60+$ & & $\begin{array}{c}1.0217^{\star *} \\
(0.009)\end{array}$ & \\
\hline $\mathrm{O}_{3}$ & & & $\begin{array}{l}0.9926 \\
(0.006)\end{array}$ \\
\hline $\mathrm{O}_{3}{ }^{\star}$ Age $50+$ & & & $\begin{array}{l}1.0081^{*} \\
(0.004)\end{array}$ \\
\hline Constant & $\begin{array}{l}0.5743 \\
(0.219)\end{array}$ & $\begin{array}{c}0.3106^{* * *} \\
(0.109)\end{array}$ & $\begin{array}{l}0.5145 \\
(0.303)\end{array}$ \\
\hline
\end{tabular}

Source: author's estimate. 
Table 14. Odds ratio of pollutants by living area.

\begin{tabular}{cc}
\hline VARIABLES & Odds Ratio (Hospital Visit) \\
\hline $\mathrm{O}_{3}$ & 0.9955 \\
& $(0.003)$ \\
$\mathrm{O}_{3}{ }^{*} \mathrm{Urban}$ & $1.0067^{\star}$ \\
& $(0.004)$ \\
Constant & $0.3730^{* * *}$ \\
Observations & $(0.124)$ \\
Number of ID & 3252 \\
\hline
\end{tabular}

Robust se form in parentheses. ${ }^{* *} \mathrm{p}<0.01,{ }^{* *} \mathrm{p}<0.05,{ }^{*} \mathrm{p}<0$. Source: author's estimate.

Table 13 \& Table 14 show the association between specific pollutants and hospital visits under different socio-economic features.

First, Table 9 focused on the association between AQI and ages since the elderly are more sensitive to the poor air quality. In this study, the age was divided into 6 groups from age 50. From the result, it is easy to find that AQI will simply increase the possibility of hospital visits in the age groups above 70. In addition, there are positive marginal effects from the interaction terms of AQI and age groups, which means the AQI will affect the possibility of hospital visits through age groups. For example, in the first column of Table 9, the interpretation is that one unit increase in AQI will increase the possibility of hospital visit by 0.0019 given the respondent is aged above 50, which calls for the attention of the negative health effects on the elderly people. The elderly people have weaker immune and defense system compared to the young people. And the poor air pollution may also lead to chain effects, such as more diseases and longer time to get recovered, which may lead to more possibility of hospital admissions. Table 10 is designed to show the health effect of air pollution given the low education level. From the result, the AQI will affect the elderly people's possibility of hospital visit given a lower education level, especially for the people under high school education. Usually, low educated people face greater health risks compared to high educated people for the following reasons: first, they do not have enough knowledge about the association between air pollution and health damage, and hardly they can take actions to reduce the harm caused by air pollution. Second, they earn less, which makes them cannot behave like rich people by avoidance behavior, such as moving to less polluted areas, pay for the air filter. Third, very few of them have the insurance, which induces that they will not go to see doctor after being harmed by the pollution. Meanwhile, they may also get fewer medical resources since they do not have insurance and live in the poor areas. Table 11 concludes the effect of AQI and its health effect based on other socioeconomic features, including gender, smoking status, marriage status, race, and the annual income. Given the feature of being male, still smoke, and earn less than 10,000 
CNY annually, we can find air pollution will increase the elderly's hospital visits, especially under the smoking status and low income. However, being married, and the race is in terms of Han makes people be less inclined to visits the hospital. Moreover, Table 12 demonstrated that people who lived in the urban area will be more inclined to visit more hospital. The reason is easy to establish that the urban area has more air pollution burden due to the vehicle emission, industries, and population while this situation does not exist in the rural area.

Table 13 and Table 14 have shown the significant health effects of specific pollutant (there are over 50 regression in total for pollutants, so only the significant ones are shown), the fixed effect logistic model was applied to study the health effects of specific pollutants by groups. And the result shows that $\mathrm{SO}_{2}$, $\mathrm{NO}_{2}$, and $\mathrm{O}_{3}$ will increase the hospital visit given certain age groups. And $\mathrm{O}_{3}$ also increases the hospital visits if the respondent is living in the urban area.

In summary, the empirical results indicate that air pollution will lead to more hospital visits through elderly age groups, which may be due to the elderly's weak immune and defense system. Also, other socioeconomic characteristics, such as low education and income, smoking habit also lead to increased hospital visits. The elderly who lives in the urban area also have more risk of visiting the hospital since more pollution was generated in the urban area. I also include the empirical study regarding the health effect of specific pollutants, which demonstrated significant effect of pollutants on the elderly's health, such as $\mathrm{SO}_{2}, \mathrm{NO}_{2}$, and $\mathrm{O}_{3}$.

\section{Conclusions}

China has unprecedented economic growth in the past decades, and it also faces the coming aging society problem in the future. In the past, great attention was put on the economic growth in measuring the development of a country. However, now we should also pay attention to how much the loss a country had, including the health loss. In addition, the care from the government is not only shown in improving education, medical system, but also providing good environment for the public, especially for the elderly people who are very sensitive.

This study found a significant impact of air pollution on increasing possibility of hospital visits for the elderly in China by applying the random effect Probit and Fixed effect Logit model. Specifically, this study discusses the health effects of air pollution given several personal or socioeconomic features, such as age, gender, income, education level. In addition, specific pollutants were also introduced into this study to discuss the impacts of individual pollutants. The results have shown that the health outcome of air pollution exhibits similarities to previous findings on the negative health effect, which suggests the importance of controlling air quality to reduce health loss and improve living quality for social planner in China.

In addition, some socioeconomic or city-level features are very important in our study, such as age, education level, annual income, marriage status, gender, 
smoking status, and race. Since certain age group or individual features indicate greater possibility of hospital visits under the same exposure of air pollution, the government should give more economic support or education of the damage caused by air pollution for these groups.

Even though there were many individual or socioeconomic features have been controlled, there are some drawbacks of this study due to the limitation of data. First, this study may not adequately control for a few confounding determinants of health outcome since air pollution is not randomly assigned across locations. In the ideal experiment, subjects would be randomly assigned to different levels of air pollution exposure, and then subsequently health effects in the high and low pollution levels would be compared. Consequently, any observed differences in outcomes could casually attribute to pollution since random assignments guarantees that differential pollution exposure would be independent of all other factors affecting health. Since randomized clinical trials are not feasible, the solution to this problem is to use an event which leads to sharp changes in air pollution across locations with a short time to identify effects of particulate matter pollution on the elderly's health. This solution leads to interest among economists in natural experiments which allow researchers to identify the effects of air pollution on health. The examples of natural experiment involve changes in environmental legislation (Greenstone and Hanna, 2011, Takana, 2015), economic activity (Chay and Greenstone, 1999), social events (He, Fan, and Zhou [13]), and plant closures (Hanna and Olivia [14]). However, in this study, the limited data source makes it hard to find an appropriate natural experiment to fit into the two-year data framework. Consequently, the comparison of health effects in the low and high polluted areas may be confounded by some unobserved determinants across regions. To solve this problem, it requires more comprehensive data for the elderly's information in the future.

Another common issue in the study of health effect of air pollution is measurement error in the air quality variable. It may lead to significant attenuation bias in the fixed effect models (Griliches and Hausman [15]). One effective econometric tool to address the measurement error problem could be using instrumental variable. Recent study attempts to use instrumental variables such as Schlenker and Walker [16]. However, the information for traffic index or transportation blocking index is still unavailable to the public in China. In addition, the accurate or approximate residence address of the respondent was not able to obtain. The data limitation leads to attenuated bias in this study. Another effective methodology is the first difference to purge the estimates of effects of time-invariant determinants of the health outcomes, such as diet or smoking. Literature using first difference include Pope, Ezzati, and Dockery [17], Ebenstein, Fan, and Greenstone (2015), Arceo, Hanna, and Oliva [7]. The difficulty of applying first difference in this study is that there were only two observations in total for each respondent in this study. With two periods data of dependent variable, it is known that first difference and fixed effect estimator are numerically 
equivalent. The application of first difference model to alleviate impacts of time-invariant variables is waiting for the release of 2015 CHARLS' wave to be added upon 2011 and 2013 waves in the coming future.

Furthermore, many studies have examined hourly, within a day or day-to-day fluctuations of pollution to identify its health outcomes. However, to match the data of the elderly, this study only uses monthly average of AQI and other pollutants as independent variable. Future work to address this problem will require daily or hourly hospital admission data in China. However, most of these data are confidential and in a range of hospital or city level, and it is hard to reach in a nationwide scale, which may fail to capture the variation of air quality within a day and its health effects.

\section{Conflicts of Interest}

The author declares no conflicts of interest regarding the publication of this paper.

\section{References}

[1] Rohde, R.A. and Muller, R.A. (2015) Air Pollution in China: Mapping of Concentrations and Sources. PLOS ONE, 10, e0135749. https://doi.org/10.1371/journal.pone.0135749

[2] Gerking, S. and Stanley, L.R. (1986) An Economic Analysis of Air Pollution and Health: The Case of St. Louis. The Review of Economics and Statistics, 68, 115-121. https://doi.org/10.2307/1924934 https://www.jstor.org/stable/1924934

[3] Harrington, W. and Portney, P.R. (1987) Valuing the Benefits of Health and Safety Regulation. Journal of Urban Economics, 22, 101-112. https://doi.org/10.1016/0094-1190(87)90052-0

[4] Greenstone, M. and Hanna, R. (2011) Environmental Regulations, Air and Water Pollution, and Infant Mortality in India. American Economic Review, 104, 3038-3072. https://doi.org/10.1257/aer.104.10.3038

[5] Tanaka, S. (2015) Environmental Regulations on Air Pollution in China and Their Impact on Infant Mortality. Journal of Health Economics, 42, 90-103. https://doi.org/10.1016/j.jhealeco.2015.02.004

[6] Chay, K.Y. and Greenstone, M. (2003) The Impact of Air Pollution on Infant Mortality: Evidence from Geographic Variation in Pollution Shocks Induced by a Recession. The Quarterly Journal of Economics, 118, 1121-1167. https://doi.org/10.1162/00335530360698513

[7] Arceo, E., Hanna, R. and Oliva, P. (2015) Does the Effect of Pollution on Infant Mortality Differ between Developing and Developed Countries? Evidence from Mexico City. The Economic Journal, 126, 257-280. https://doi.org/10.1111/ecoj.12273

[8] Moretti, E. and Neidell, M. (2011) Pollution, Health, and Avoidance Behavior: Evidence from the Ports of Los Angeles. The Journal of Human Resources, 46, 154-175. https://doi.org/10.3368/jhr.46.1.154 https://www.jstor.org/stable/25764807

[9] Ebenstein, A., Fan, M. and Greenstone, M. (2015) Growth, Pollution, and Life Ex- 
pectancy: China from 1991-2012. American Economic Review, 105, 226-231. https://doi.org/10.1257/aer.p20151094

[10] Zhang, D., Liu, J. and Li, B. (2014) Tackling Air Pollution in China-What Do We Learn from the Great Smoke of 1950s in London. Sustainability, 6, 5322-5338.

https://doi.org/10.3390/su6085322

[11] Wang, X., Dickinson, R.E., Su, L., Zhou, C. and Wang, K. (2018) $\mathrm{PM}_{2.5}$ Pollution in China and How It Has Been Exacerbated by Terrain and Meteorological Conditions. Bulletin of the American Meteorological Society, 99, 105-119. https://doi.org/10.1175/BAMS-D-16-0301.1

[12] Wooldridge, J.M. (2013) Introductory Econometrics: A Modern Approach. 5th Edition, South-Western, Mason, $\mathrm{OH}$.

[13] He, G., Fan, M. and Zhou, M. (2016) The Effect of Air Pollution on Mortality in China: Evidence from the 2008 Beijing Olympic Games. Journal of Environmental Economics and Management, 79, 18-39. https://doi.org/10.1016/j.jeem.2016.04.004

[14] Hanna, R. and Oliva, P. (2015) The Effect of Pollution on Labor Supply: Evidence from a Natural Experiment in Mexico City. Journal of Public Economics, 122, 68-79. https://doi.org/10.1016/j.jpubeco.2014.10.004

[15] Griliches, Z. and Hausaman, J. (1986) Errors in Variables in Panel Data. Journal of Econometrics, 31, 93-118. https://doi.org/10.1016/0304-4076(86)90058-8

[16] Schlenker, W. and Walker, W.R. (2015) Airports, Air Pollution, and Contemporaneous Health. The Review of Economic Studies, 83, 768-809.

https://doi.org/10.1093/restud/rdv043

[17] Pope, C.A., Ezzati, M. and Dockery, D.W. (2009) Fine-Particulate Air Pollution and Life Expectancy in the United States. The New England Journal of Medicine, 360, 376-386. https://doi.org/10.1056/NEJMsa0805646 